\title{
From the Editorial Desk
}

\author{
Dilip Mukherjee ${ }^{1}$
}

Published online: 14 December 2021

(C) Zoological Society, Kolkata, India 2021

Dear readers,

You may recall that the Editorial Board of the Proceedings of the Zoological Society(PZOS) Springer Nature decided in the early part of this year to launch a special issue of the journal every year beginning 2021. We also informed you that each special issue will be dedicated entirely to a contemporary topic of scientific as well as societal importance. Accordingly, the theme of the maiden issue was suggested as the biological impacts of endocrinedisrupting chemicals (EDCs). We invited original research articles, short communications and review articles from the eminent researchers in the field globally. The response was overwhelming despite the fact that most of the Institutes remained closed due to Covid pandemic for a prolonged period. In fact, many of the researchers were not in aposition to submit their articles in time.

Today I am pleased to announce the publication of the inaugural special issue of our journal PZOS on 'The biological impacts of endocrine-disrupting chemicals (Editors: Dilip Mukherjee, Manas Ranjan Ray, Parthiba Basu and Guillia Guerriero). The aim of this issue is to bring together international and national experts to provide a comprehensive view of this topic of environmental and public health importance.

The impacts attributed to the EDCs include a range of reproductive problems such as early puberty, infertility, changes in hormonal levels, polycystic ovary syndrome (PCOS) along with altered thyroid metabolism; metabolic syndrome including obesity, type 2 diabetes,

Dilip Mukherjee

dilipmukher@ rediffmail.com

1 Kolkata, India cardiovascular and renal complications; brain and behavioral problems; impaired immunity, and various cancers and also deleterious effects of EDCs on the endocrine systems of the animals of almost all phyla of vertebrates as well as some invertebrate phyla, You will find an update on many of these topics in the 20-plus articles published in this special issue.

I take this opportunity to acknowledge the researchers who contributed even after experiencing a difficult and depressing time being locked at home for more than a year and half. I also acknowledge those investigators who, despite their best efforts, could not contribute their articles to this issue in this harrowing time. I am certain to get their support to the journal in future.

I like to acknowledge the Springer group for their constant support rendered during the processing of the articles that we received. My sincere thanks to the President, VicePresident and Secretary of the Zoological Society, Kolkata for their constant inspiration to achieve our goal. Our distinguished reviewers, my colleagues in the Editorial Board, and Editorial Assistant Dr. Anisa Mitra (Assistant Professor, Department of Zoology, Sundarban Hazi Dasarat College) deserve my heartfelt gratitude and special thanks for their tireless efforts and enthusiasm in processing the articles. I would like to acknowledge the contribution of Supratim Laha, Ph.D. fellow, Department of Zoology, University of Calcutta for the cover page illustration of this special issue.

My dear readers, we are always open to your views and 
valuable suggestions for further improvement of the journal. Therefore, I solicit your feedback on this special issue. I will be delighted if you kindly contact me at any time at journal mail id zoolsocietykol@gmail.com with questions you may have or ideas that you like to share with us.

Stay safe and secured.

Best wishes from Team PZOS for a happy, healthy and prosperous New Year-2022.
Prof. Dilip Mukherjee.

Editor -in-Chief.

Proceedings of the Zoological Society (PZOS).

Dated: 14. December, 2021.

Publisher's Note Springer Nature remains neutral with regard to jurisdictional claims in published maps and institutional affiliations. 